\title{
The Effects of Reading Goals on Learning in a Computer Mediated Environment
}

\author{
Betsy A. Schoeller \\ University of Wisconsin - Milwaukee, WI, USA
}

schoeller@sois.uwm.edu

\begin{abstract}
This study measured the effects of reading goals on learning in a computer mediated environment. Reading goals are defined as the purpose one has for reading. Learning is defined as adding to one's prior knowledge. A computer mediated environment is defined as reading text from a computer monitor. 125 undergraduates ( 77 females) were given one of three reading goals: read to understand the text, read to take a test, or read to teach the material to another student. Then the participants read a long (3000+ words) passage of text from a computer screen. A computer program written in Microsoft QuickBasic 4.5 (copyright by Microsoft) presented the text on the screen four lines at a time, and measured how long students spent on each page initially, how many times students re-read pages, and how much time students spent re-reading pages. Half of the participants read passages with headings, while the other half read passages without headings. Learning was measured in three ways: recall of the main topics and supporting details of the passage, time spent reading each page of text and time spent re-reading pages, and number of times pages were re-read. Recall of supporting details was significantly greater for the teaching goal than the testing goal. Time spent re-reading was significantly greater for the teaching goal. Students with the knowing goal recalled significantly more supporting details than students with the testing goal. These findings suggest that reading goals do have an effect on learning in a computer mediated environment.
\end{abstract}

Keywords: Reading goals, Computer-mediated environment, Learning, Learning from text

\section{Introduction}

The literature indicates that skilled adult readers rely heavily on reading goals as they apply reading strategies in a purposeful way. They set reading goals, vary reading style depending upon how relevant the text is to those reading goals, read ahead and back in the text to find information relevant to their reading goals, and are aware of their progress toward their reading goals (Pressley \& Afflerbach, 1995; Pressley, Brown, El-Dinary, \& Afflerbach, 1995; Wyatt et al., 1993). Taraban, Rynearson and Kerr (2000) found a consistent relationship between reading goals, reading strategy and grade point average.

There is also a substantial body of recent literature on goal orientation as a motivational charac-

Material published as part of this journal, either on-line or in print, is copyrighted by Informing Science. Permission to make digital or paper copy of part or all of these works for personal or classroom use is granted without fee provided that the copies are not made or distributed for profit or commercial advantage AND that copies 1) bear this notice in full and 2) give the full citation on the first page. It is permissible to abstract these works so long as credit is given. To copy in all other cases or to republish or to post on a server or to redistribute to lists requires specific permission from the publisher at Publisher@InformingScience.org teristic of the learner. McWhaw and Abrami (2001) were concerned with the effects of interest in subject matter versus actual rewards (payoffs) for performance on topic recall. While this is an interesting new development in the field, a different sense of the term 'reading goal' is used in the context of this study. The present experi- 
ment is focused on task manipulation more than an abiding characteristic (motivation) of the learners. This focus on task manipulation is important because, in an instructional setting, students are often asked to learn material for which they do not have high interest, and most instructional settings do not provide immediate payoffs. In other words, the present study is more concerned with specific goals for a text where interest may be low to moderate and the goals are manipulated by the task assigned to the student.

Surprisingly, there is very little recent research on the manipulation of the task assigned to the student for studying a passage. The literature indicates that reading goals are crucial to successfully learning from text, but there is a lack of research on whether providing a learner with a specific reading goal will improve learning from text. The purpose of this study is to determine if learning in a computer mediated environment can be improved by giving learners explicit reading goals.

\section{Reading Goals and Learning}

Learning, for the purpose of this study, is defined as the ability to read text and correctly recall the main topic as well as recall supporting details about the passage. Predictably, some readers recall well-written text better than others. But many readers fail to recognize main topics altogether, and although some readers can verbalize the main idea of the text, very few can verbalize how they know what is important in a passage (Schoeller \& Surber, 2003). Students reading traditional text often terminate studying too soon, not even completing the reading assignment. It appears that even "good" adult readers, like college undergraduates, read in a way that is unsophisticated, inefficient, and ineffective from the perspective of information-processing (Pressley, ElDinary, \& Brown, 1992; Wood, Motz, \& Willoughby, 1998). This problem is exacerbated in electronic text by hypertext, since hypertexts cause an additional processing load, making the reader responsible for navigating the text. Hypertext actually adds a greater amount of interference, making it harder to integrate the information (Folz, 1996).

Anderson and Armbruster (1982) argue that giving students any type of information concerning the nature of the learning goal will facilitate performance. Students were asked to read with a particular goal in mind; they were told that they would be expected to take a test after they have read some text. When one group of students was told to expect a multiple choice test and the other group was told to expect a completion test, the results were not very conclusive. In fact, D'Ydewalle, Swerts and De Corte (1983) noted that the most conspicuous outcome of this research was the "inconclusiveness of the findings" (p. 55). In an attempt to clarify the issue of learning goals on reading, D'Ydewalle et al. had more conclusive results when they manipulated expectation of test mode. Two history passages were used, each followed by a test. After studying the first history text, college students immediately received a test consisting of either completion questions or multiple-choice items. They were led to expect the same type of test after studying a second text. Study time was self-paced, and the type of test was either the expected or unexpected one. Students expecting completion questions after the second text used more study time and performed better on both types of tests than did students expecting a multiple-choice tests.

It appears that there is indeed a difference in the way subjects read, depending upon their reading goal. There is also inconclusiveness to the question of learning and how it is affected by reading goals. This study will explore the issues of how learning is affected by reading goals.

\section{Theoretical Framework}

There is a substantial body of knowledge centered on how we learn from text. Reviewing the process of learning from text and notions which underlie successful and unsuccessful reading will put this study into context. During the last half of the 20th century one major theory of verbal 
learning was developed to the point of dominating all work on verbal learning. This theory is typically referred to as Propositional Network Theory, and though there have been challenges to the theory, it is by far the most complete verbal learning theory developed. The most current detailed presentation of Propositional Network Theory appears in a book by Kintsch (1998) where he has extended the theory to account for a wide range of research on human cognition. Most current research does not attempt to challenge Propositional Network Theory but, rather, uses the theory itself as a guide for specific questions within the theory.

When a student reads, the objective is for the student to acquire knowledge which can be stored in long term memory, available for future use. The type of knowledge gained from reading text is not procedural (how to DO something), but is declarative (or verbal) knowledge. The smallest unit of declarative knowledge is the proposition. Anderson (1985) defines a proposition as the "smallest unit of knowledge that can stand as a separate assertion." Propositions are unelaborated, concrete, and specific ideas.

Basically, Propositional Network Theory says that verbal information is added to memory one proposition at a time. Though there are differences in the very definition of a proposition across different versions of Propositional Network Theory, generally a proposition is described as a simple statement that is shorter than most sentences (e.g. The tree is green). When propositions occur at the same time (co-occur) connections are made between propositions and they are stored together in long term memory IF they have something in common. That something could be as simple as a single word, or it could be a more complex idea, like the main topic of a discourse. With additional co-occurrences encouraging more connections between propositions, webs of meaning, or propositional networks, are formed and added to long term memory (Gagne, Yekovich, \& Yekovich, 1993). As a person is exposed to many examples of an experience, abstractions begin to form. As the webs of meaning continue to become more complex and even more abstractions are formed, they help to organize similar, related information.

Sometimes people can build large organized networks of propositions which are conceptually related (usually called schemas). A schema is the organization of an expert's well-understood knowledge. In 1932, Bartlett introduced the idea of schema; the abstractions that result from tying together strings of propositional networks into a highly elaborated, hierarchical organization of knowledge. Information integrated into schema can be recalled and applied later. It can also be the case that people (especially students learning unfamiliar topics) may just have "lists" of disorganized propositions loosely associated in memory. Students' propositional webs (or networks) may be fragmentary, incomplete, poorly organized and dependent on only one cue for retrieval. It is the same result one might expect from poorly memorized material. In a sense, the present study will explore some of the conditions that lead to organization in memory versus just details in lists. Learning is said to take place when ideas are added to schema, and there are a number of processes that need to take place to be able to form a schema. Processes are sets of productions with the goal of extracting the essence of meaning from the passage that is read.

\section{Disruptions to Learning}

It is possible for things to go wrong in the process of knowledge acquisition. A disruption in the process could prompt misinformation to be added to the student's understanding of what is being read, or make it very difficult for the student to process very much of the information at all. This is particularly problematic when the goal is to remember the important points in the text, or reconstruct the information (take a test) or transfer the knowledge (teach the information to someone else). There are three categories which could disrupt the process contributing to learning: student factors, text factors, and task factors (Gagne, Yekovich \& Yekovich, 1993). 


\section{Student Factors}

There are many points in the reading process when students can unknowingly and without malice sabotage their own efforts to learn from text. There could be a lack of literal comprehension altogether, or a misunderstanding of the literal meaning of the section of text. If a student does not possess literal comprehension, or has a misunderstanding of the literal meaning, integration, summarization and elaboration could well be affected.

\section{Text Factors}

McNamara, Kintsch, Songer and Kintsch (1996) demonstrated the importance of text being well written. Text written with insufficient structure and importance cues is said to be inconsiderate. Inconsiderate text, which is more difficult to read because it is not as structurally logical, can lead to comprehension failure. Inconsiderate text could easily undermine both literal comprehension and inferential comprehension. It is very difficult for a reader of inconsiderate text to acquire the propositions needed to facilitate schema development. When nouns are replaced with pronouns, and descriptive phrases and connections between ideas are removed, it is possible for readers with prior knowledge to compensate by inferring the relations not specifically stated in the text. On the other hand, more novice readers are more likely to make incorrect inferences or misunderstand the text completely. Readers without relevant prior knowledge need to read a fully coherent, very explicit text in order to construct an appropriate representation of what was expressed.

Considerate text can facilitate schema development through (1) early presentation of importance cues and thematic statements tying together text details, (2) careful sequencing of related ideas, and (3) the use of familiar text organizations in structuring text information (Charney, 1994). Potentially, these sorts of cues can be controlled to even a greater extent with a computer than from traditional text.

\section{Task Factors}

Task factors are the reasons we read (i.e., reading goals). If we read differently depending on those reading goals, task factors could also disrupt the comprehension process. Although literal comprehension and integration would likely not be affected by task factors, summarization could be affected adversely. If a student were aware that $\mathrm{s} /$ he needed to be able to summarize to have a good understanding of the text, the task could affect progress by adding a sense of urgency to reading, because the task is driving the activity. But the task itself would not disrupt the summarization process. Elaboration is much the same. If a student is aware on some level that elaboration will add meaning and make it easier to remember, reconstruct and transfer the knowledge, it might add a feeling of wanting to be able to elaborate in order to complete the task.

The task would not disrupt the goal setting and strategy selection, but might guide the student to choosing more appropriate goals and strategies. It would be the same with goal checking and remediation. The task would not disrupt the goal checking process, but might make the student more aware that the learner needed to check goals, and might make the student more likely to remediate if goals were not being reached. Of the three factors that can disrupt the process of knowledge acquisition, the most difficult to control directly is student factors. Most students approach learning from reading with a limited set of skills and typically those skills are not best suited for a thorough understanding of the text (Baker, 1989; Simpson, 1984). Generally, we tend to work with whatever skills the students bring to an educational setting. We can, however, identify and control text so it is more likely that students will learn from it. This has been documented. The remaining, task factors, is directly related to reading goals, an area not well researched and full of inconclusive findings. Since task factors are directly related to reading goals, 
perhaps if we could identify reading goals that are more conducive to learning, we could provide an optimal learning environment for each student.

\section{Focus of This Study}

The focus of this study is on the reading task (i.e. goal) and how it affects learning, reading patterns and study patterns. Specifically, this study will examine differences in learning, reading patterns and study patterns in a computer mediated environment when the reader has a specific reading goal in mind. In addition, carrying out the reading goals will be facilitated in approximately half the participants with passages in which subtopics are clearly marked by headings. Headings signal the topics in the text, so it would be expected that these two factors will interact to affect learning, reading patterns and study patterns. Participants with the reading goal to teach and who read the passages with headings would be expected to best learn main topics and supporting detail.

\section{Learning}

There are a variety of methods to measure student learning outcomes, and the most common are: multiple choice, fill-in-the-blank, short answer, and essay questions (which may include problem solving). The learning outcomes focused on in this research will look at the extent to which the learners acquire a schema for the information presented in the text. In other words, will the participants be able to gain enough information from the text to build a mental representation (or schema) that approximates an expert in the subject area (so they are able to recall main topics and some supporting detail). At this time there are no standard methods for measuring a schema. Nevertheless, if it can be shown that the participants know the main topics of the text, the supporting details for these main topics, and the relationships among these pieces of information, this would indicate that the learners are on their way toward acquiring a schema. This study will use a method developed by Surber (1997) which is intended to measure how well students recall main topics and supporting detail. By asking participants to recall two to five main topics and one to five subtopics for each main topic, this open ended task provides an opportunity for learners to show what they know about the material. It is also possible that a learner would display misunderstandings about the information. Misunderstandings of the text will often result in idiosyncratic responses pointing toward inconsiderate text. Since the text being used in this study is considerate text, and facilitates the development of an integrated text representation, these types of idiosyncratic responses are not expected.

\section{Reading Patterns}

One way to measure reading behavior is through the use of time. Much of the time research in reading has focused on eye tracking and eye behavior during reading. Monty and Senders (1983) reported measuring the speed of word and letter identification. Rayner and Pollatsek (1987) took an interdisciplinary approach to timed reading research which included eye-tracking studies, as well as a cognitive-anatomical approach to studying word recognition. PET scans were used to indicate that different cortical areas of the brain are activated by different word recognition tasks. The work of Just and Carpenter (1987) on eye fixations suggest that longer eye fixations occur when readers are confronted with uncommon words, while they are integrating information from important clauses in the text, and while making inferences at the ends of sentences. While the scope of the present study does not specifically include the detail of eye fixation, longer reading times might suggest differences in reading behavior. Do students spend more time reading and rereading passages when their reading goals are different? Work done by Surber (1994) suggests there is no significant difference between reading text in print and reading the same text from a computer screen. 
For this study, a computer program written in Microsoft QuickBasic 4.5 (copyright Microsoft) will read a passage of text from the text file and present the text on the screen in four-line page segments. Subjects will be able to move backward and forward through the passage with single keystrokes. In this manner, subjects can easily re-read previous passages if they desire, and the computer program measured the amount of time students spend reading a page for the first time, and the amount of time students spend re-reading pages.

\section{Studying Patterns}

Since the goal for most reading is comprehension, it is important for students to make decisions about whether they comprehend the passages they are reading. If a student decides $\mathrm{s} / \mathrm{he}$ does not comprehend the passages, s/he must use some strategy to solve this problem by adjusting studying patterns accordingly. One strategy was identified by Garner and Reis (1981), who found that good comprehenders consistently recognized comprehension problems and used "look-back" strategies to solve them (looking back in the text when a student realizes s/he needs more information from preceding pages). Do students spend more time re-reading pages depending on their reading goals? As students navigate back and forth through the screens of text, the computer program used in this study tracked the number of times pages were viewed, so there was a count of how many times students went back to re-read pages.

\section{Research questions}

1. Do learning outcomes change with different reading goals? (e.g., which group has higher recall: reading to teach with or without headings, reading to test with or without headings, or reading to understand with or without headings?)

2. Are different reading patterns used for different reading goals? (e.g., which group spends more time reading and re-reading: reading to teach with and without headings, reading to test with and without headings, or reading to understand with and without headings?)

3. Are different studying patterns used for different reading goals? (e.g., which group rereads more times: reading to teach with and without headings, reading to test with and without headings, or reading to understand with and without headings?)

\section{Methodology}

\section{Participants}

For this study a convenience sample from a large public university in Wisconsin was used. Wallen and Fraenkel (2001, p. 137) define convenience sample as "a group of individuals who (conveniently) are available for study." There were 125 subjects, 77 female. Ages ranged from 18 to $43,(\underline{M}=24, \underline{S D}=5.4)$. Students' class standing was based on the number of credit hours earned at the university. $2.4 \%(\underline{\mathrm{N}}=3)$ of the participants were freshmen, $7.2 \%(\underline{\mathrm{N}}=9)$ were sophomores, $44 \%(\underline{N}=55)$ were juniors, and $46 \%(\underline{N}=58)$ were seniors. These undergraduate students were granted extra credit points as an incentive for participating in the study. Volunteers were recruited from the School of Information Studies' Bachelor of Science in Information Resources program $(46.4 \%(\underline{\mathrm{N}}=58))$ and from an introductory educational psychology class taken primarily by Education students $(42.4 \%(\underline{\mathrm{N}}=53))$. The remaining participants $(11.2 \%(\underline{\mathrm{N}}=14))$ represented Speech and Language Pathology $(\underline{\mathrm{N}}=10)$, Finance $(\underline{\mathrm{N}}=1)$, Psychology $(\underline{\mathrm{N}}=1)$, Math $(\underline{\mathrm{N}}=1)$, and Spanish $(\underline{\mathrm{N}}=1)$ degrees. 


\section{Materials}

Reading Task: The reading task was a 3000+ word passage (3299 words with headings, 3271 words without headings) on the causes of aging in humans. The passage was written as considerate text. It facilitated the development of an integrated text representation because it accomplished three major goals of considerate text: (1) tied together text details with early presentation of importance cues and thematic statements (topic statements were presented early and tied together the supporting details which were mentioned later in the text paragraph), (2) carefully sequenced related ideas, and (3) structured text information with the use of familiar text organizations (Charney, 1994). The reading task was presented in the computer lab on a computer monitor. Reading from the monitor enhanced the ability to log reading time per page, re-reading time per page, and the number of visits per page. The text was presented in four-line 'pages' on a computer screen. Reading was self paced and readers were allowed to page forward and back through the text. The computer recorded the total amount of time spent on each page (read plus re-read). Additionally, students were able to take notes if they desired.

Verbal Ability Task: In order to better measure learning of the passage, a distracter task was administered. This 84-item vocabulary test was sufficiently long enough that participants were likely not able to finish in the six minutes allotted. As a result, this task also served as a "timefiller" to ensure that responding to the test on the passage was not from short term memory.

Recall Task: The recall task consisted of a sheet of paper with instructions at the top which asked the participant to list two to five main topics of the passage. This was followed with additional instructions asking the participants to list one to five subtopics for each of the main topics they had listed. This task was the primary measure of learning. By stating the number of topics and subtopics as a range and not using exact numbers, the participants were given little cuing of the expected responses and the participants were given the opportunity to tell any misunderstandings as well as correct responses. Participants were not permitted to use any notes taken during the reading portion of the study to assist with recall.

Questionnaire: The questionnaire collected demographic information for each of the participants. Questions included the participants' year in school, whether they had prior knowledge of the reading task, and how interesting they found the passage.

Computer Program: The text was presented to subjects by means of a computer program written in Microsoft QuickBasic 4.5 (copyright Microsoft). The program read the passage from a text file and presented the text on the screen in four-line page segments. Subjects were able to move backward and forward through the passage with single keystrokes. In this manner, subjects easily re-read previous passages if they desired. The program recorded how much time the subjects spent on each four-line page for the first time read and also a cumulative total of any re-reading time.

\section{Procedure}

Each participant was seated at one of the four computer stations in the lab. Participants were given a short online warm-up passage to read in order for them to become accustomed to the presentation of text and the functions of the keys. Only two navigation keys were used by the participants; one key (pg down) to advance to the next screen of text, and one key (pg up) to go back to the previous screen. Participants were asked to practice using the keys until they felt comfortable, and all participants were observed to quickly become accustomed to the navigation, switching from one screen to the next (or previous). No students appeared to be uncomfortable or distressed in any way with the navigation system. A third key (quit) was available to participants should they decide to terminate the study. Participants were told that they could terminate the 
study at any time, but all students chose to complete the entire study and all of its associated tasks.

When participants indicated they were comfortable with the reading process, they were told that they would be reading text from the computer screen. Each student was given a packet of study materials in which each task was color-coded for clarity of instruction. Participants removed the first set of materials, and read the instruction sheet which gave the reading goal (to understand the passage, or to take a test about the passage, or to be able to teach the passage). Each was then asked to read the text passage from the screen at his/her own pace. Specifically, one group was told to read a passage to understand it. A second group was told to read the same material in order to prepare for taking a test. A third group was told to read the same material in order to teach the material. Half of the subjects in each group read the passage with the five sections marked by headings, while the other half read without the benefit of headings. Participants were allowed to work at their own pace, reading and re-reading as they saw fit, and participated in note-taking if they wished. All questions asked by participants of the study were clarification questions, and were answered individually by the researcher.

All participants had the passage presented to them in a four-line window on a computer monitor. The passage for this study had 88 'pages' when presented four lines at a time. In previous research when this same text was presented on a computer, the 'page' size varied from single words at a time (for very short passages less than one print page) to entire screens. The argument has been made (Surber, 1992, 1994) that any unit size is to some extent arbitrary (book pages often end in mid-sentence). The decision of 'page' length in this context became a matter of timing: many short pages would allow for fine-grained reading times; while a smaller number of pages would contain more text with less fine-grained reading times. In this study, one factor of interest is the use of headings (or lack of headings) to signal the structure of the text. With four-line pages, headings were sufficiently surrounded by text and also were short enough to provide a better measure of reading times than fewer, longer pages. This particular configuration has been used effectively in a number of previous studies (Schoeller \& Surber, 2003; Surber, 1992, 1994).

When all sections of the text had been read, participants were given a distracter task; a timed vocabulary test. Then participants were asked to complete the recall task. Finally, each participant was asked to complete the questionnaire. Each group read the same passage under the same conditions with different goals in mind. The groups were compared to see if different goals elicited differences in comprehension.

Three research questions addressed provide the basis for the research predictions for this study: Do learning outcomes change with different reading goals? Are different reading patterns used for different reading goals? Are different studying patterns used for different reading goals? In the following three sections, those general questions are stated as specific predictions about differences in recall, reading patterns, and studying patterns for the groups in the study. Learning was measured by scoring the recall task. Reading patterns were measured by comparing the reading time and re-reading time for each page. Study patterns were measured by comparing number of re-reads for each page. Predictions were based on the premise that reading goals would affect the recall, reading patterns and study patterns of the groups. Knowing that s/he would be teaching the material should have enhanced learning from the text, seen in an increase in recall, reading times, and number of rereads. Additionally, participants reading text enhanced with headings should have shown an increase in recall over those reading text without headings.

Learning: One way to measure learning is to measure recall. In attempting to see the effects of reading goals on learning, overall recall was expected to be

1. Greater for the teaching goal with headings included than any other group; and 
2. Greater for the teaching goal than any other goal (regardless of headings).

Reading Patterns: In this case, the effect of reading goals on reading patterns was measured by comparing amount of time spent reading and rereading. Time spent reading and re-reading was expected to be

1. Greater for the teaching goal with headings included than any other group; and

2. Greater for teaching goal than any other goal (regardless of headings).

Studying Patterns: The effect of reading goals on studying patterns was measured by comparing the number of times the participants re-read passages of the text. The expectation was that number of rereads would be

1. Greater for the teaching goal with headings included than any other group; and

2. Greater for the teaching goal than any other goal (regardless of headings).

\section{Results}

\section{Scoring}

Three sets of data were scored: (1) the recall task in which participants were asked to recall the main topics and supporting ideas for those topics; (2) read and re-read times, measuring how much time was spent reading a page the first time, and any time spent re-reading pages; and (3) number of times pages were re-read.

Recall: To score the recall task, each of the written responses was scored with a procedure already developed for a pilot study and used in similar research (Schoeller \& Surber, 2003; Surber, 2001). The theme of the passage was causes of aging. The intent of measuring recall was to see what the individual learned. If learning is the ability to organize information into a schema, recall of both the main topic and supporting details are important. There were five main topics in the passage. Recall of the five main topics was scored using a $0,1,2$ scale. A ' 0 ' was given if the subject did not identify the main topic, a ' 1 ' was given if the subject could identify the gist of the main topic but could not clearly state the main topic, and a ' 2 ' was given if the subject could clearly identify the main topic. A total of 10 points was possible for the recall of all five main topics. Additionally, recall of supporting details was measured. Although recall of supporting details was an important indication that learning occurred, if a participant only remembered specific details about spinning and fasting and the Fountain of Youth, and didn't remember the main topics (that hormonal influences cause aging and genetic programs cause aging), the organization of information was more fragmentary and true learning still wasn't achieved. Recalling two supporting details was sufficient for measuring learning without taking away from the importance of also recalling main topics. For each of the five sections, a maximum of two supporting details was scored. If a participant recalled no supporting details in a section, they were given a score of ' 0 ' for that section. If a participant recalled one supporting detail in a section, they were given a score of ' 1 ' for that section. If a participant recalled more than one supporting detail in a section, they were given a score of ' 2 ' for that section. A total of 10 points was possible for the recall of supporting details in the five main topic sections. Initially a sample test set of recall protocols was coded by two evaluators independently. The differences were discussed in an attempt to converge on a consistent judgment process. Then the entire set of protocols was scored by each rater independently and the percent of agreement was computed for the whole set. When any differences remained, single scores were obtained by resolving the differences in conference. As a result, each participant received one set of scores for topic, and one set of scores for supporting details. The overall percent of agreement between the two raters was 91 . 
Time: The raw time scores (in milliseconds) as measured by the computer program were saved in separate files for each participant by the computer program. Some preliminary steps were taken with the data before individual reading speed was accounted for. First, the data from the first and last page of the passage were not included. It was observed that many subjects failed to follow instructions, and unknowingly began the timer on the first page before they were instructed to do so. Since they had learned to advance the text in the warm-up, students tended to automatically advance the screen before hearing the experimenter ask the participants to read the instructions which indicated the reading goal. This added inordinate amounts of time to the first page times while they read the reading goal and focused back on the reading task. Additionally, when the participants were finished reading the text, they routinely neglected to advance the screen one last time (although there is on-screen prompt to do so), so the timer was not stopped. This added inordinate amounts of time to the last page of text. Finally, all times were converted to seconds for clarity of presentation.

Re-reads: The computer program automatically kept a count of the number of times each page was reread. These re-reads were summed for each individual. The final data set included the following scores for each participant:

a) Main topic recall (range $=0-10)$;

b) Supporting detail recall (range $=0-10$ );

c) Total time of initial read for each page;

d) Total time spent re-reading each page;

e) Total number of pages re-read;

f) Data for each item of the questionnaire.

Prior to the main analyses reported below, variables a-f were screened for irregularities such as outliers, skewness, and homogeneity of variance. None of the analyses for variables a-e reported instances of outliers. F-max tests for all variables revealed no violations of the homogeneity of variance assumption. Specific results for the questionnaire will be discussed in more detail in the results section.

\section{Analysis}

Research Design: This study used a 3 x 2 factorial between-subjects design reading goal (know, test, teach) $\mathrm{x}$ heading condition (headings, no headings).

Recall: Total recall (sum of main topic recall and supporting detail recall) was expected to be:

1. Greater for the teaching goal with headings included than any other group;

2. Greater for the teaching goal than any other goal (regardless of headings) tested by reading goal pairwise tests.

As mentioned earlier, it was anticipated that headings would enhance recall. Since the heading condition had the potential to have a differential effect on the main topic and supporting details, a repeated measures analysis of main topic and supporting detail recall was necessary in order to see if the heading condition made a difference in how much was recalled. Recall scores were then analyzed using a $2 \times 3 \times 2$ between- by within-subjects factorial design with the last factor being within-subjects (heading condition (headings, no headings) x reading goal (know, test, teach) $\mathrm{x}$ recall (topic, supporting detail)). Table 1 presents the descriptive statistics of this $2 \times 3 \times 2$ design. 


\begin{tabular}{|l|l|c|c|c|c|c|c|}
\hline Reading Goal & & \multicolumn{3}{|c|}{ Main Topic } & \multicolumn{3}{c|}{ Supporting Detail } \\
\hline & Heading Condition & $\underline{\mathrm{N}}$ & $\underline{\mathrm{M}}$ & $\underline{\mathrm{SD}}$ & $\underline{\mathrm{N}}$ & $\underline{\mathrm{M}}$ & $\underline{\mathrm{SD}}$ \\
\hline Know & & & & & & & \\
\hline & Headings & 21 & 2.90 & 1.89 & 21 & 6.10 & 1.81 \\
\hline & No Headings & 21 & 2.43 & 2.13 & 21 & 5.71 & 1.87 \\
\hline Test & & & & & & & \\
\hline & Headings & 21 & 2.57 & 1.78 & 21 & 4.81 & 2.02 \\
\hline Teach & No Headings & 21 & 2.71 & 1.59 & 21 & 5.00 & 1.82 \\
\hline & & & & & & & \\
\hline & Headings & 20 & 3.55 & 2.16 & 20 & 6.65 & 1.66 \\
\hline & No Headings & 21 & 2.29 & 2.10 & 21 & 6.38 & 1.80 \\
\hline
\end{tabular}

Table 1: Descriptive Statistics for Recall

The analysis of variance for recall with main topic and supporting detail as the repeated measures resulted in no significant effect for the heading condition. There was a significant interaction between the reading goal and recall factors $(\underline{\mathrm{F}}(2,119)=8.3, \mathrm{p}=.000, \underline{\mathrm{MSE}}=27.4)$. There was also a significant effect for recall $(\underline{\mathrm{F}}(1,119)=174.6, \underline{\mathrm{p}}=.000, \underline{\mathrm{MSE}}=574.6)$. There were no other significant effects or interactions.

To test the specific pairwise predictions, independent t-tests were conducted for reading goals, with supporting detail as the dependent variable. As significant difference was found between the knowing goal and the testing goal $(\mathrm{t}(82)=2.5, \mathrm{p}=.016)$. The mean of the knowing goal $(\underline{\mathrm{M}}=5.9$, $\underline{\mathrm{SD}}=1.8)$ was significantly larger than the mean of the testing goal $(\underline{\mathrm{M}}=4.9, \underline{\mathrm{SD}}=1.9)$. A significant difference was also found between the testing goal and the teaching goal $(\mathrm{t}(81)=4.0, \mathrm{p}=.000)$. The mean of the teaching goal $(\underline{\mathrm{M}}=6.5, \underline{\mathrm{SD}}=1.7)$ was significantly larger than the mean of the testing goal $(\underline{\mathrm{M}}=4.9, \underline{\mathrm{SD}}=1.9)$. There was no significant difference between the knowing goal and the teaching goal.

Time: Time spent reading and re-reading was expected to be

1. Greater for the teaching goal with headings included than any other group.

2. Greater for the teaching goal than any other goal (regardless of headings).

Time scores were analyzed separately in a $2 \times 3$ between-subjects analysis of variance (heading condition (headings, no headings) x reading goal (know, test, teach)). Table 2 presents the descriptive statistics for reading time and re-read time. With read time as the dependent variable, no significant effects or interactions were found. With re-read time as the dependent variable, there was a significant main effect for goal $(\underline{F}(2,119)=10.30, \underline{p}=.000, \underline{M S E}=1033431.40)$. There were no other significant effects or interactions for re-read time.

\begin{tabular}{|l|l|r|r|r|r|r|r|}
\hline Reading Goal & & \multicolumn{3}{|c|}{ Read Time } & \multicolumn{3}{c|}{ Re-read Time } \\
\hline & Heading Condition & $\underline{\mathrm{N}}$ & $\underline{\mathrm{M}}$ & $\underline{\text { SD }}$ & $\underline{\mathrm{N}}$ & $\underline{\mathrm{M}}$ & $\underline{\text { SD }}$ \\
\hline Know & & & & & & \\
\hline & Headings & 21 & 1119.70 & 244.38 & 21 & 56.28 & 83.10 \\
\hline & No Headings & 21 & 1140.77 & 303.07 & 21 & 88.23 & 138.07 \\
\hline Test & & & & & & \\
\hline & & 21 & 1271.36 & 260.28 & 21 & 78.52 & 70.94 \\
\hline Teach & Headings & 21 & 1240.01 & 464.99 & 21 & 166.60 & 114.10 \\
\hline & No Headings & & & & & & \\
\hline & Headings & 20 & 1273.11 & 272.23 & 20 & 301.49 & 527.03 \\
\hline
\end{tabular}

Table 2: Descriptive Statistics for Reading Time (measured in seconds) 
Independent t-tests were conducted to test specific predictions about goal effects on each of the dependent variables of read and re-read time. Results of the comparisons between the knowing goal and teaching goal found significant differences for both read time $(\underline{t}(81)=2.40, p=.019)$, where the mean of the teaching goal $(\underline{\mathrm{M}}=1297.50$ (21.63 minutes), $\underline{\mathrm{SD}}=357.80)$ was significantly larger than the mean of the knowing goal $(\underline{M}=1130.20$ (18.84 minutes), $\underline{S D}=272.10)$, and for reread time $(\mathrm{t}(81)=3.43, \underline{\mathrm{p}}=.001)$, where the mean of the teaching goal $(\mathrm{M}=359.30$ (5.99 minutes), $\underline{\mathrm{SD}}=529.00)$ was again significantly greater than the knowing goal $(\underline{\mathrm{M}}=72.30$ (1.21 minutes), $\underline{\mathrm{SD}}=113.70)$. Comparisons between the testing and teaching goal only resulted in differences in re-read time $(\underline{\mathrm{t}}(81)=3.20, \mathrm{p}=.002)$. Significant differences were revealed between the mean of the teaching goal $(\underline{\mathrm{M}}=359.30$ (5.99 minutes), $\underline{\mathrm{SD}}=529.00)$ and the mean of the testing goal $(\underline{\mathrm{M}}=97.60$ (1.63 minutes), $\underline{\mathrm{SD}}=95.80)$. There were no other significant differences found.

Pages Re-read: It was expected that the total number of pages re-read would be

1. Greater for the teaching goal with headings included than any other group.

2. Greater for the teaching goal than any other goal (regardless of headings).

Number of pages re-read was analyzed in a $2 \times 3$ between-subjects (heading condition (headings, no headings) $\mathrm{x}$ reading goal (know, test, teach)) ANOVA. There were no significant effects or interactions found.

Questionnaire: Demographic results from the first four questions on the questionnaire concerning gender, age, class standing and major in school were presented earlier. The rest of the responses (questions 5-9 on the questionnaire) are presented below. A chi-square analysis was performed on question 5 to examine whether there was any association between question response patterns and reading goal (i.e., know, test, teach). Due to empty cells and small expected cell counts, chisquares analyses were not performed on the remaining questions, however, graphical displays are presented for each remaining question (i.e., 6, 7, 8, \& 9).

Question 5 asked, "Compared with reading a text book, reading on the computer is" Possible responses were: (1) Easier than reading from a book; (2) About the same as reading from a book; (3) More difficult than reading a book. Responses to this question were analyzed in a $3 \times 3$ chisquare (response $(1,2,3) \mathrm{x}$ reading goal (know, test, teach)) analysis. There was an association between reading goal and response patterns $\left(\chi^{2}(4, n=125)=14.59, p=.006\right)$. Over half of individuals in the know condition indicated that reading from a computer was the same as reading print text, whereas about half of individuals in the test and teach conditions indicated that reading from the computer was more difficult than reading from print text.

A correlation of ease of reading from a computer and recall revealed no correlation $(r=.04)$ between participants' ease of reading from a computer and what they recalled. Likewise, there was no correlation $(\mathrm{r}=.05)$ between participants' ease of reading from a computer and read time, and a small correlation $(\mathrm{r}=.16)$ between ease of reading from a computer and number of pages reread. There was, however, a correlation $(\mathrm{r}=.20, \mathrm{p}=.024)$ between participants' ease of reading and re-read time. In other words, individuals that found it more difficult reading from a computer than reading from a book, tended to spend more time re-reading pages.

Question 6 asked, "Have you taken any online classes?" Possible responses were: (1) I've taken online classes and passed all of them; (2) I've taken online classes, passing some and failing others; (3) I've taken online classes and failed all of them; (4) I've never taken online classes. Across all reading goal conditions, just over $60 \%$ of individuals had never taken an online class and between $28 \%$ and $38 \%$ had taken an online class and passed.

Question 7, which asked, "How much did you know about the topic of the passage before you read it?" There were four possible responses: (1) I had never read/heard anything about the topic; 
(2) I think I read/heard something about the topic once; (3) I have read/heard about the topic a number of times; (4) I could discuss the topics of this passage in detail. The majority of individuals across all reading goals had heard about the topic once before the study $(48 \%, 64 \%, 68 \%$, respectively). The relationship between prior knowledge and recall revealed a small positive correlation $(\mathrm{r}=.12)$ between participants' prior knowledge and what they actually recalled.

Question 8 asked, "How interesting did you find the reading?" Possible responses were: (1) Very interesting; (2) Moderately interesting; (3) Not very interesting; (4) Not interesting at all. The majority of individuals in each reading goal condition found the reading passage moderately interesting $(55 \%, 62 \%, 63 \%$, respectively). A negative correlation $(\mathrm{r}=-.18, \mathrm{p}=.04)$ was found between participants' interest and what they actually recalled. Given the order of the response options, the inverse correlation indicates that those individuals who found the reading more interesting also tended to score higher on recall.

Question 9 asked, "How well do you think you did on the task which asked you to recall the topics?" Possible responses were: (1) I got all the important information; (2) I got most of the important information; (3) I may have gotten one of the main points; (4) I did not remember any of the passage. Just over $80 \%$ of individuals in the know reading condition indicated that they recalled most of the important information, whereas, about half of individuals in the test and teach reading goal conditions indicated a similar response. A negative correlation $(r=-.29, p=.001)$ was found between participants' estimated success and what they actually recalled. Once again, considering the order of response options, the inverse correlation indicates that those individuals who felt they did well on recall of information also tended to score higher on actual recall.

\section{Discussion}

This study found that of the three reading goals, to know the passage, to take a test of material learned in the passage and to teach the passage, specific detail recall and re-read time increased for subjects with the teaching goal. Reading with the idea that they would be teaching the material made a difference in how many supporting details they recalled. Headings had no significant effect on recall, reading time, or times re-read. One major expectation of this study was that recall would be greater for the teaching goal with headings included than any other group, and that recall would be greater for the teaching goal than any other goal (regardless of headings). The latter was confirmed by the data; students with the teaching goal performed better on the supporting detail recall than students with the testing goal, regardless of headings. Further, data supported significant differences in recall of supporting detail between teaching and testing goals and between testing and knowing goals.

Another expectation of this study was that reading times would be greater for the teaching goal with headings included than any other group, and that times would be greater for the teaching goal than any other goal (regardless of headings). This prediction was partially confirmed in that there was a significant difference in reading times between the teaching and knowing goal, but no differences between any other pairs of goals. Additionally, data support significant differences in re-reading times between the teaching goal and the testing goal and the teaching goal and the knowing goal, with no difference between the other pair of goals. Specifically, there were no differences in reading or re-reading times between the knowing and testing goals, and no difference in reading times between the testing and teaching goals. In addition, there were no interactions with the headings factor.

It was also expected that the number of pages re-read would be greater for the teaching goal with headings included than any other group, and that times would be greater for the teaching goal than any other goal (regardless of headings). This expectation was not supported by the data. Finally, there were some interesting results regarding the questionnaire. Although an association 
was found between ease of reading on the computer and reading goal, there was no correlation between ease of reading from a computer and recall. These results are consistent with the existing body of literature suggesting there are no differences in recall between reading from a computer screen and reading from print text. Also, there were inverse correlations between the participants' perception of how interesting the passage was and recall, as well as participants' perception of recall success and actual recall. So participants who found the reading more interesting were more likely to score higher on recall. Likewise, participants who felt they did well on the recall tended to score higher on recall.

\section{Conclusion}

Of the three reading goals used in this study, the teaching goal did significantly better in supporting detail recall than the testing goal. Students with the teaching goal recalled more supporting details than the other two goals. Since instructors typically expect students to remember supporting details on tests, this finding is notable. Students reading with the teaching goal took greater time reading the passage than students in either of the other goals. They also took more time rereading than either of the other goal groups. This suggests that students know that they need to spend more time reading and comprehension checking when they have a teaching goal. Giving learners a reading goal to teach has been done in one prior study by Schommer \& Surber (1986). The researchers were primarily interested in learners' monitoring of their own test readiness and did not look at either recall patterns or study patterns. Therefore, the present findings represent a substantial extension of this work. Students with the teaching goal spent more time reading and recalled more of the supporting details from the passage.

Students with the testing goal recalled significantly less than students with the teaching goal. Students with the testing goal also spent significantly less time reading and re-reading than students who had the teaching goal. Students with the knowing goal recalled significantly more supporting details than students with the testing goal. Students with this goal also spent significantly less time reading than the teaching goal, specifically in re-reading time. Although this might seem surprising, there is a substantial body of evidence that students expecting a test typically overestimate their knowledge and do not study enough (Bol \& Hacker, 2001).

Apart from recall of supporting detail, students with the testing goal did not perform significantly better or worse than the knowing goal. The failure to find a difference between testing goal and the knowing goal is not a serious mystery. Students tend to expect to be tested in experiments (Orne, 1962). Because of this, the goals to test and know may have essentially been the same goals for those participants.

There are other questions left unanswered that should be considered for future research: headings made no significant difference to any goal. This is puzzling given the substantial body of research supporting headings (Baumann, 1986; Lorch, 1989). If we know that considerate text is optimal for learning, why didn't headings make any significant impact? One possibility is that the vast majority of research using narratives (including instructional text) used passages often no longer than a paragraph or two and rarely longer than four pages (about 1000 words). This includes the research conducted by Lorch (1989) and Baumann (1986). With these relatively short passages of text headings might have made a larger impact on the subjects since more of the total text is comprised of headings. The text used in this study is considered to be very long by comparison (3000+ words), and perhaps the headings didn't have the same impact on the participants. Another possibility to consider is that the passage has an organization that is clear to learners even without headings. Of the five main topics the first introduces the passage by describing symptoms of aging and traditional 'cures' and the last section focuses on the future of aging research. The three middle sections discuss the three main types of causes of aging: cell damage, hormones, and genetic causes. Repetition alone may provide cues to importance; cell damage is mentioned 59 
times, hormones 22 times, and genes 36 times. Previous work (Surber, 2001; Surber \& Pallock, 1997) has shown that frequency of mention of a phrase is sufficient to affect the likelihood that readers will recall that phrase as an important topic even when it is not. To account for the differences among groups, it may be the case that the readers who had the teaching goal were willing to make the effort to use whatever cues were available when headings were not available. In contrast, readers in the other groups simply had the strategy of reading through the passage in a cursory manner. This notion is consistent with the fact that the teaching goal group read more slowly through the passage.

Perhaps there is something about the content on individual pages that make a difference in recall or time spent on each page. One direction which could be taken for future research would be to explore the possibility that more information could be gained by stopping students when they turn a page and asking them to respond to a cue word that appears on the screen. Students would need to indicate whether the cue word is relevant to what they have just been reading, or irrelevant. Response times and responses could be measured by the computer presentation software. Unfortunately, the software used in the present experiment would not permit that manipulation.

Another possible area of study is the correlation between participants' perceptions and actual recall. There is already a notable body of literature that shows there is no difference between reading from a computer screen and reading print text. But the questionnaire also revealed a small correlation between participants' interest in the passage and recall. Perhaps an area of further research could center on this relationship, and may link in some way to recent research concerning motivation and learning. Finally, a correlation was found between participants' perception of recall success and actual recall. This contradicts a notable body of literature that shows that students are consistently unreliable in their estimates of what they know. This result also warrants further research.

Additionally, this study suggests that giving students the reading goal to be able to teach the information increases their recall of supporting details. Since many tests measure the amount of supporting details students remember, this could have implications for instruction. Students with the goal to teach remember more supporting detail, which means they are more likely to perform better on tests which measure recall of supporting detail. Perhaps it would be useful to have students actually teach material to someone else as a course requirement. This could be the basis of a multi-session study in which students read a passage and produce a PowerPoint presentation of the topics and important details. Since none of the groups did significantly better at recalling main topics, it would be interesting to see if producing a PowerPoint presentation would result in better recall for main topics or supporting details. This would be another exciting direction for future research.

\section{References}

Anderson, J.R. (1985). Cognitive psychology and its implications ( ${ }^{\text {nd }}$ ed.). San Francisco: Freeman.

Anderson, T. H. \& Armbruster, B. B. (1982). Reader and text-studying strategies. In W. Otto \& S. White (Eds.). Reading expository material New York: Academic Press.

Appleyard, J.A. (1994). Becoming a reader: The experience of fiction from childhood to adulthood. Cambridge, England: Cambridge University Press.

Baker, L. (1989). Metacognition, comprehension monitoring, and the adult reader. Educational Psychology Review, 1, 3-38.

Bartlett, F.C. (1932). Remembering: A study in experimental and social psychology._ambridge, England: Cambridge University Press. 
Baumann, J.F. (1986). Effect of rewritten content textbook passages on middle grade students' comprehension of main ideas: Making the inconsiderate considerate. Journal of Reading Behavior, 1, 1-21.

Boettcher, J., \& Conrad, R. (1999). Faculty guide for moving teaching and learning to the web. Mission Viejo, California: League for Innovation in the Community College.

Bol, L. \& Hacker, D.J. (2001). A comparison of the effects of practice tests and traditional review on performance and calibration. Journal of Experimental Education, 69, 133-152.

Charney, D. (1994). The impact of hypertext on processes of reading and writing. In S. J. Hilligoss \& C. L. Selfe (Eds.), Literacy and computers. New York: Modern Language Association.

D'Ydewalle. G., Swerts, A., \& DeCorte, E. (1983). Study time and test performance as a function of test expectations. Contemporary Educational Psychology. 8, 55-67.

Faust, M. A. \& Glenzer, N. (2000). 'I could read those parts over and over': Eighth graders rereading to enhance enjoyment and learning with literature. Journal of Adolescent \& Adult Literacy. 44, 234-240.

Foltz, P. W., (1996). Comprehension, coherence, and strategies in hypertext and linear text. In J. F. Rouet, J. J. Levonen, A. Dillon \& R. J. Spiro (Eds.), Hypertext and cognition (pp. 109-136). Mahwah, NJ: Erlbaum.

Gagne, E. D., Yekovich, C.W., \& Yekovich F. R. (1993). The cognitive psychology of school learning (2 ${ }^{\text {nd }}$ ed.). New York: Harper Collins.

Galef, D. (Ed.). (1998). Second thoughts: Focus on rereading. Detroit, MI: Wayne State University Press.

Garner, R. \& Reis, R. (1981). Monitoring and resolving comprehension obstacles: An investigation of spontaneous text lookbacks among upper-grade good and poor comprehenders. Reading Research Quarterly, 16, 569-582.

Johnson, M. (1985). The art of rereading: Prolegomenon to a contemporary pedagogy of poetry. Journal of Aesthetic Education, 19, 37-49.

Just, M.A., \& Carpenter, P. A. (1987). The psychology of reading and language comprehension. Newton, MA: Allyn and Bacon.

Kintsch, W. (1986). Learning from text. Cognition and Instruction, 3, 87-108.

Kintsch, W. (1988). The use of knowledge in discourse processing: A construction-integration model. Psychological Review, 95, 163-182.

Kintsch, W. (1998). Comprehension: A paradigm for cognition. Cambridge: Cambridge University Press.

Lorch, F. F. (1989). Text-signaling devices and their effects on reading and memory processes. Educational Psychology Review, 1, 209-234.

Martinez, M., \& Roser, N. (1985). Read it again: The value of repeated readings during storytime. The Reading Teacher, 38, 782-86.

McNamara, D.S., Kintsch, E., Songer, N. B., \& Kintsch, W. (1996). Are good texts always better: Interactions of text coherence, prior knowledge, knowledge, and levels of understanding in learning from text. Cognition and Instruction, 14(1), 1-43.

McWhaw, K. \& Abrami, P.C. (2001). Student goal orientation and interest: Effects on students' use of selfregulated learning strategies. Contemporary Educational Psychology, 26, 311-329.

Monty, R.A. \& Senders, J. W. (Eds.). (1983). Eye movement and psychological processes. Hillsdale, NJ: Erlbaum.

Nist, D. (1996). Effects of rereading. Reading Psychology, 17, 137-157.

Orne, M.T. (1962). On the social psychology of the psychological experiment: With particular reference to the demand characteristics and their implications. American Psychologist, 17, 776-783. 
Perez, S. (1989). Rereading to enhance text understanding in the secondary classroom. Reading Horizons, $30,62-66$.

Pressley, M., \& Afflerbach, P. (1995). Verbal protocols of reading: The nature of constructively responsive reading. Hillsdale, NJ: Erlbaum

Pressley, M., Brown, R., El-Dinary, P.B., \& Afflerbach, P. (1995). The comprehension instruction that students need: Instruction fostering constructively responsive reading. Learning Disabilities Research and Practice, 10, 215-224.

Pressley, M., El-Dinary, P. B., \& Brown, R. (1992). Skilled and not-so-skilled reading: Good information processing and not-so-good information processing. In M. Pressley, K. Harris, \& J. Guthrie (Eds.), Promoting Academic Competence and Literacy in School (pp. 91-127). San Diego, CA: Academic Press.

Protherough, R. (1994). Read it once, read it twice. In B. Corcoran, M. Hayhoe, \& G. Pradl (Eds.), Knowledge in the making: Challenging the text in the classroom. Portsmouth, NH: Heinemann.

Rayner, K., \& Pollatsek, A. (1987). Eye movements in reading: A tutorial review. In M. Coltheart (Ed.), Attention and performance XII: The psychology of reading. Hillsdale, NJ: Erlbaum

Samuels, S. J. (1997). The method of repeated readings. The Reading Teacher, 50, 376-381.

Sanjivamurthy, P. T. \& Kumar, V. K. (1983). Test mode anticipation and performance: A classroom experiment. Contemporary Educational Psychologist, 8, 355-365.

Schoeller, B. A. \& Surber, J. R., (2003). Using think-aloud strategies to gain insight on how importance is determined by readers of text. Unpublished manuscript, University of Wisconsin-Milwaukee.

Schommer, M. \& Surber, J.R. (1986). Comprehension monitoring failure in skilled adult readers. Journal of Educational Psychology, 78, 353-357.

Simpson, M. L., (1984). The status of study strategy instruction. Journal of Reading, 28, 136-142.

Sullivan, Z. (1991). Theory for the untheoretical: Rereading and reteaching Austen, Bronte, and Conrad. College English, 53, 571-579.

Surber, J. R., (1992). The effect of test expectation, subject matter, and passage length on study tactics and retention. Reading Research and Instruction, 31, 32-40.

Surber, J. R., (1994). Identification of important elements in lengthy instructional text. Reading Research and Instruction, 33, 175-186.

Surber, J. R., (2001). Effect of topic label repetition and importance on reading time and recall of text. Journal of Educational Psychology, 93, 279-287.

Surber, J. R., \& Pallock, L. (1997). Effect of topic frequency and position on memory for information from lengthy informative text. Contemporary Educational Psychology, 22, 390-398.

Taylor, V. C. (1999). The effects of textmaps on learning from electronic text._Unpublished doctoral dissertation, University of Wisconsin - Milwaukee.

Tsai, C. (1988). Hypertext: Technology, applications, and research issues. Journal of Educational Technology Systems, 17, 3-14.

Van Dijk, T. A., \& Kintsch, W. (1983). Strategies of discourse comprehension. New York: Academic Press.

Wallen, N.E., \& Fraenkel, J. R. (2001). Educational research: A guide to the process. Mahwah, NJ: Lawerence Erlbaum Associates.

Whelan, D. L. (2002). Congress passes TEACH act. School Library Journal, 48 (11), 19.

Wood, E., Motz, M., \& Willoughby, T. (1998). Examining students' retrospective memories of strategy development. Journal of Educational Psychology, 90, 698-704. 
Wyatt, D., Pressley, M., El-Dinary, P., Stein, S., Evans, p., \& Brown, R. (1993). Comprehension strategies, worth and credibility monitoring, and evaluations: Cold and hot cognition when experts read professional articles that are important to them. Learning and Individual Differences, 5, 49-72.

\section{Biography}

Dr. Betsy Schoeller is the Distance Education Coordinator in the School of Information Studies at the University of Wisconsin - Milwaukee, USA. Her current research interests include distance learning, cognition and learning, organization of knowledge and indexing. 